\title{
Preventing damage to floating foils caused by Rayleigh-Taylor instabilities
}

\author{
John O. Stoner, Jr., Robert B. Stoner, and Constance G. Stoner \\ ACF-Metals, PMB 231, 2954 N. Campbell Avenue, Tucson AZ, U.S.A. 85719-954
}

\begin{abstract}
An evaporated metal foil target is often produced on a layer of water-soluble parting agent previously applied to a massive substrate. The foil is then floated onto a water surface by immersing the substrate into a water bath. and is picked up later if the foil survives. During the foil's release, a significant fraction of the dissolved parting agent may remain close to the floating foil, as a "heavy" thin layer of solution having higher density than water. This layer of parting agent solution and the lower-density water bath below it form a gravitationally unstable configuration known as a Rayleigh-Taylor instability. If the foil is sufficiently thin, its mass and elastic properties can be ignored, and the motion of the liquids is determined by only the liquids' properties. This system can spontaneously adjust itself toward stability in several ways, one of which involves rotating a cylindrical liquid cell having a horizontal axis, and its cylindrical surface tangent to the surface. This motion moves part of the heavy layer from the top surface downward. The target maker detects this occurrence by the motions of the foil floating on the top of the bath; if the foil is frail, these motions may result in the crumpling, wrinkling, or tearing of the foil. We have observed such behavior with aluminum foils having thickness of $37 \mathrm{~nm}$ and diameter of $920 \mathrm{~mm}$ on $\mathrm{NaCl}$ parting agent, and have successfully implemented methods to prevent such damage.
\end{abstract}

To use free-standing thin metal foils with thicknesses below one micron, it is often necessary to release (float) them from their substrates and mount them on frames. We found that sufficiently large and thin foils were destroyed by convection during this floatoff. No one had warned us about this. So we had to learn how to prevent it.

We made evaporated metal foils on evaporated water-soluble parting agent previously applied to massive substrates. The foils were aluminum, on sodium chloride parting agent on plastic sheet substrates.

These foils were thinner and larger than average; they were intended to be $37 \mathrm{~nm}$ thick $\left(10 \mu \mathrm{g} / \mathrm{cm}^{2}\right)$ and $920 \mathrm{~mm}$ in diameter, to investigate the feasibility of foilneutralizing large-diameter beams of $\mathrm{H}^{-}$ions. The substrates were Lexan squares approximately $1.2 \mathrm{~m}$ x 1.2 $\mathrm{m}$ (Fig. 1). Each foil required cleaning one Lexan sheet substrate, evaporating a uniform layer of $300 \mathrm{~nm}$ of $\mathrm{NaCl}$ parting agent, then evaporating a uniform layer of $37 \mathrm{~nm}$ of $\mathrm{Al}$. This process required about three days to manufacture each foil.

After evaporation, each foil was floated onto a water surface by suspending the foil's substrate in a wooden tub lined with polyethylene sheet, having dimensions approximately $1.22 \mathrm{~m} \times 2.5 \mathrm{~m} \times 1.22 \mathrm{~m}$ deep, and slowly raising the water level (Fig. 2). If the foil survived, it was then picked up onto a large flat nickel mesh having approximately 10 wires/cm, on a ring support, with $920 \mathrm{~mm}$ inner diameter. The mesh on its ring waited under water for the foil to be floated; then the water level was lowered by siphoning to lower the foil onto the mesh.

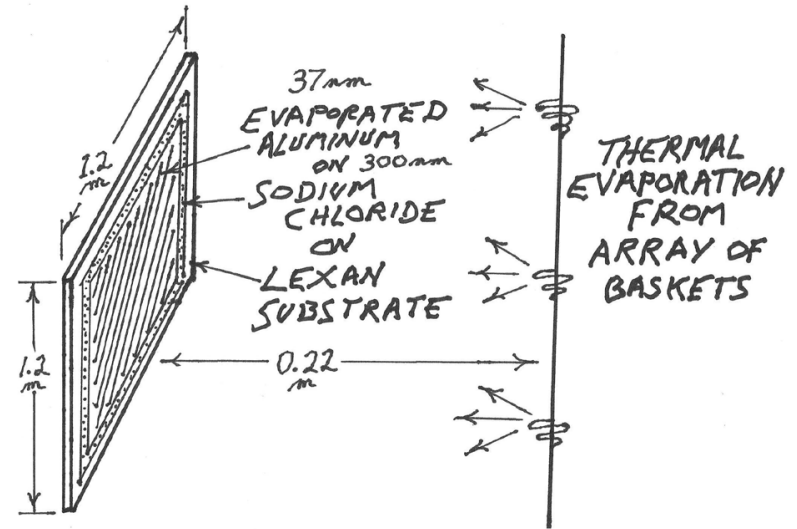

Fig. 1: Simplified sketch of evaporation method for $\mathrm{NaCl}$ and Al.

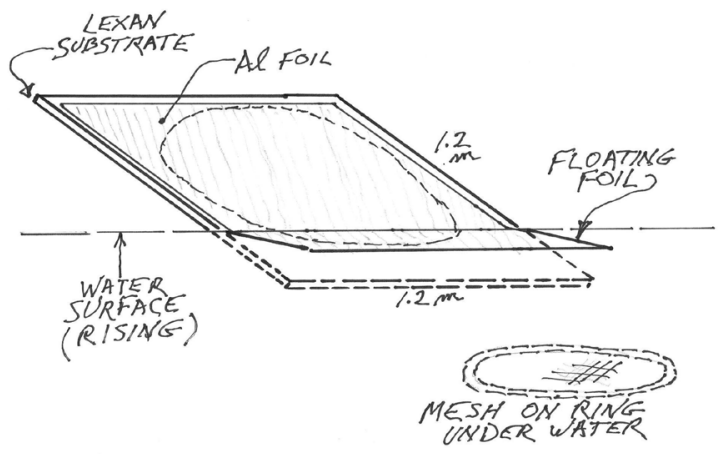

Fig. 2: Floatoff geometry. 
We needed only one successful foil. However, we had to make eight of them to get one success; the others all failed unexpectedly by collapsing during floatoff. We finally hypothesized that the problem arose from the parting agent. During the foil's release, a significant fraction (perhaps fifty percent) of the dissolved parting agent remained close to the floating foil, as a "heavy" thin layer of solution having higher density than water (Fig. 3).

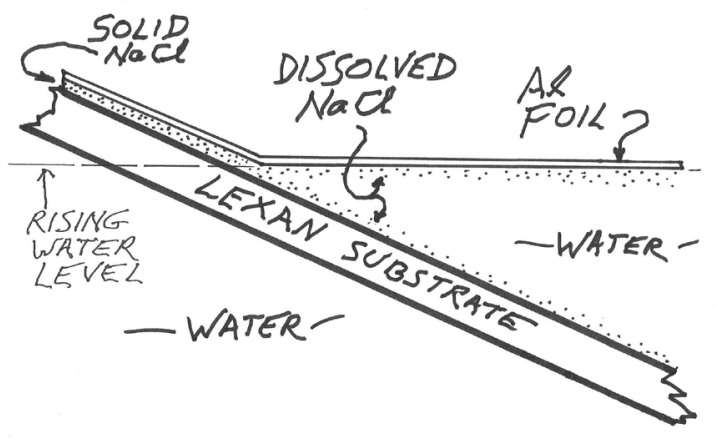

Fig. 3: Detail of parting agent during floating.

The upper layer of parting agent solution on top of the lower-density water bath formed a gravitationally unstable configuration known as a Rayleigh-Taylor instability (Fig. 4) [1].
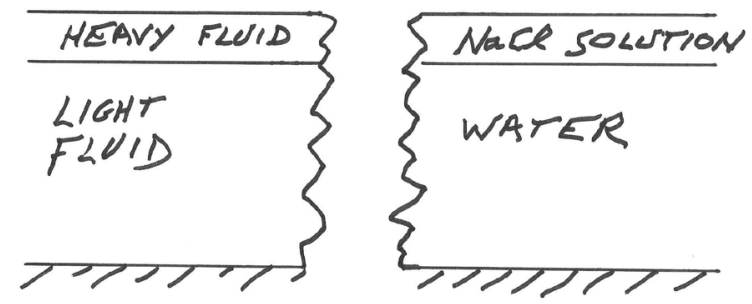

Fig. 4: A Rayleigh-Taylor instability consists of a relatively dense fluid layer above a less-dense fluid layer.

The foil was sufficiently thin that its mass and elastic properties could be ignored, so that the motion of the liquid was controlled primarily by the liquids' properties. Any relatively dense fluid layer remaining slightly above the Lexan substrate was presumed to have little effect. This system could spontaneously adjust itself toward stability in several ways, one of which involved rotating a cylindrical liquid convection cell having a horizontal axis, with its cylindrical surface tangent to the water surface. This motion moved part of the heavy layer from the top surface down to the bottom (Fig. 5).

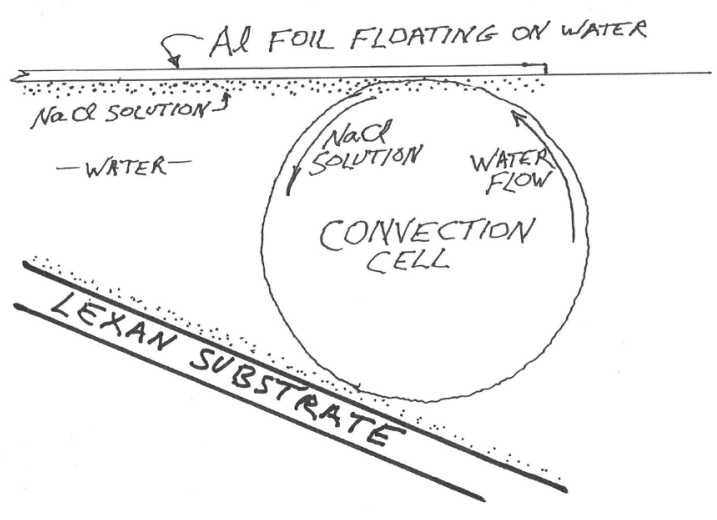

Fig. 5: Convection in a parting-agent-water system.

The target maker detected this occurrence by sudden motions of the foil floating on the top of the bath; the foil was sufficiently frail that these motions resulted in the crumpling, wrinkling, and/or tearing of the foil (Fig. $6)$.

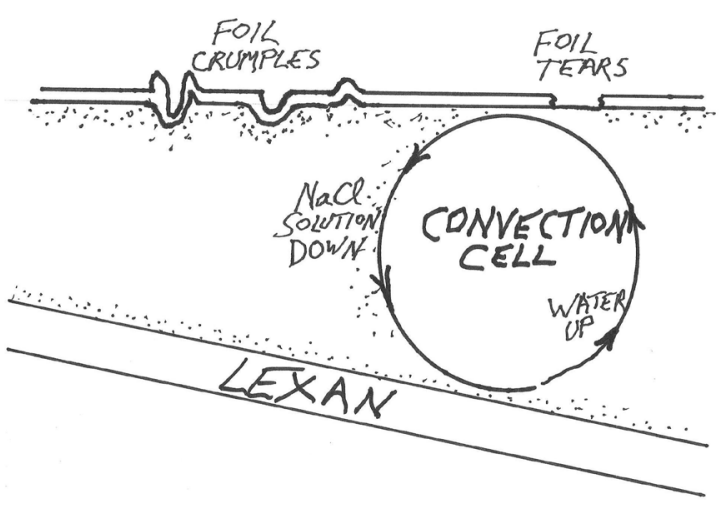

Fig. 6: Damage to floating foil caused by convection.

Fig. 7 shows an example of a foil that demonstrated tearing and collapsing, or crumpling. This is an aluminum foil, about $920 \mathrm{~mm}$ diameter, thickness about $37 \mathrm{~nm}$, evaporated onto $300 \mathrm{~nm}$ of sodium chloride parting agent. Immediately after it had been completely floated this foil suddenly collapsed in less than $10 \mathrm{~s}$, staying on the water surface. It also tore at several places and broke out a large area, before it was captured on its mesh. 


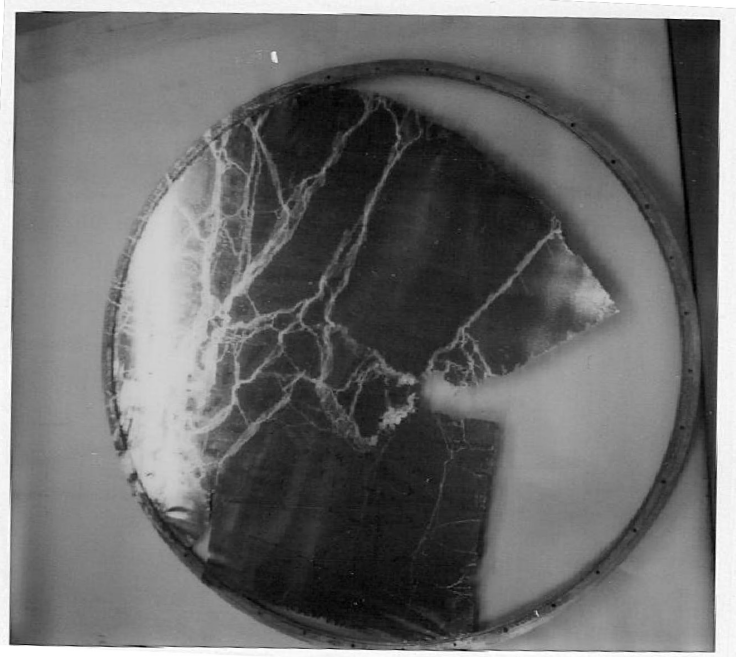

Fig. 7: Foil that wa $8.5 \mathrm{~s}$ torn and collapsed by convection prior to its pickup on a mesh.

We considered several other mechanisms that might cause crumpling or collapsing, and could rule out most of them:

A contaminant film spreading on the water surface might compress the floating foil. But no such film could be found.

Surface tension irregularities might occur due to localized impurities on the Lexan substrate's surface. Pre-washing the Lexan showed no obvious impurities, making this unlikely.

Cooling of the top surface of the float water by evaporation could easily cause convection, simply due to density differences, or also involving temperaturedependent surface tension differences. To minimize the likelihood of these effects, we started each float process by putting half a ton of ice in the bottom of the float tank, to cool the bottom water and make certain that the water in the tank was always warmer toward the top.

The water and the parting agent solution were transparent so we could not directly see convection cells move. We decided that if we could stop them, we did not need to make them visible, so we placed a thin flat "barrier" Lexan sheet a few centimeters below the foil (Fig. 8). As the level of the float water was raised to release the Al foil from its substrate, the barrier sheet was moved toward the substrate. This reduced the coupling of the heavier $\mathrm{NaCl}$ solution to the lighter water in the float tank.

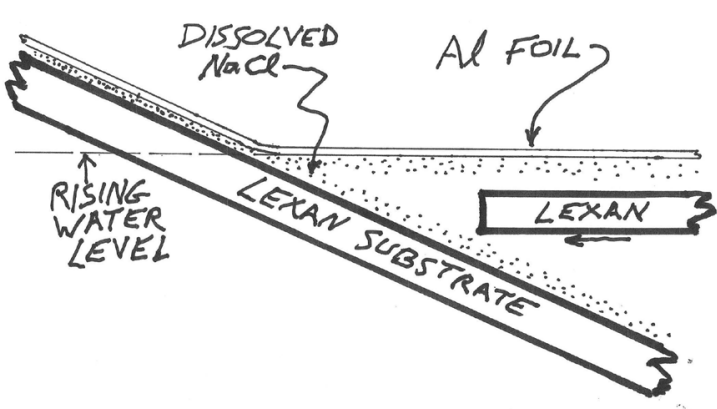

Fig. 8: "Barrier" Lexan sheet placed to prevent large convection cells from reaching the floating foil.

This solved the problem - no more sudden catastrophes occurred during the floating process. We were then able to float off and pick up foil \#8, this 920-mm diameter Al foil, without any crumpling or tearing (Fig. 9).

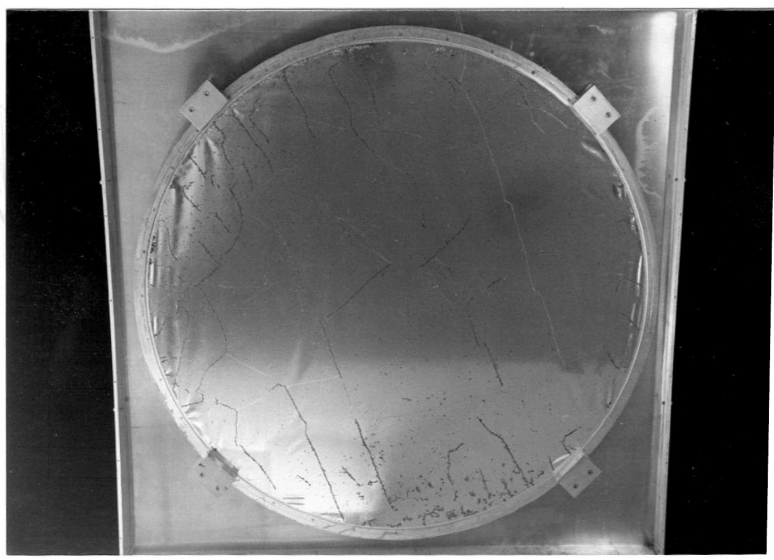

Fig. 9: A foil that was floated and mounted on a mesh without damage by convection.

We concluded that, although convection of the float water represented a serious threat to preparation of large thin foils, the threat could be contained by careful placement of barriers preventing large convection cells from reaching the floating foils.

\section{References}

1. D.H.Sharp, Physica D: Nonlinear Phenomena, 12, 1-3, 3-18 (1984) 